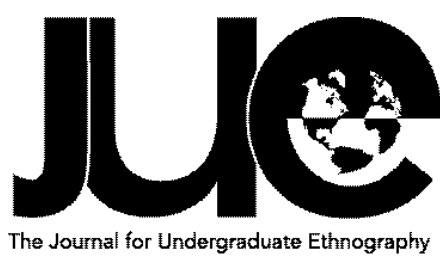

Volume 3 | Issue 2

\title{
Large Americano, Extra Masculine: How People Do Gender at The Coffee House
}

Aubrey Limburg

Portland State University, alimburg@pdx.edu

ABSTRACT

his research examines the way in which customers in an urban cafe "do gender." This research expands existing literature on doing gender in organizational settings by making the customer the focus of the analysis of gender presentations in public spaces. The findings are based on ethnographic research that was conducted over the course of eight weeks in an urban Northwestern city in the United States. My findings suggest that male and female customers most commonly performed hegemonic masculinity and emphasized femininity, respectively. These performances were further pronounced when analyzed in the context of heterosexual relationships, where accountability for gender presentations became even more salient. The way that customers interacted with employees reinforced already normative presentations of gender.

Keywords: doing gender, hegemonic masculinity, emphasized femininity 


\section{INTRODUCTION}

In "Doing Gender," West and Zimmerman (1987) created a theory that posits that gender is a social accomplishment rather than an essential component of sexed bodies. They argue that, "[d]oing gender means creating differences between girls and boys and women and men, differences that are not natural, essential, or biological" (West and Zimmerman 1987, 137). Gender, therefore, is not an innate experience of human existence, but rather a social construct that is reproduced through social interaction. West and Zimmerman (1987), then, see individuals' gender performances as accountable to culturally normative conceptions of gender (p. 136). This perspective allows for gender to be studied in a social context which gives insight into the way in which individual gender performances are affected by internal or external forces. Therefore, I use the concept of doing gender as the primary theoretical framework to understand the way in which customers do gender at an urban cafe in the Northwestern United States, The Coffee House.

\section{"Our social world is built on systemic structural inequality based on gender; social life reproduces both gender difference and gender inequality." - Kimmel}

\section{LITERATURE REVIEW}

Scholars have applied West and Zimmerman's (1987) concept of doing gender to the context of work and employment. This research has looked at a broad array of occupational contexts, including: bankers (Forseth 2005), servers (Hall 1993, Hall 1993, LaPointe 1992, Tibbals 2007), fast food workers and insurance agents (Leidner 1991), exotic dancers (Trautner 2005), doctors and nurses (Davies 2003), and police officers (Rabe-Hemp 2009). While some studies assess the effect of customers on workers' gender performances, there has been little research done with a focus on gender performances of customers. In Hall's (1993) article, "Smiling, Deferring, and Flirting: Doing Gender by Giving 'Good Service,"' she discusses the ways in which the gender performances of servers changes depending on the customer. In one instance she states that one of the servers "turns up the charm... smiles a lot more for women... to a table of business men... a little more distant... don't talk as much... waitresses play up to the business men" (p. 461). Therefore, the service that is provided is based on the gender and gender performances of the customer. This was not an unconscious endeavor, as servers articulated that they were aware of the way they were rewarded: tips and positive interactions due to normative gender performances. In the article, "Serving Hamburgers and Selling Insurance," Leidner (1992) looks at the way in which gender is 
performed by workers in interactive service jobs. In the article she states: "These workers were closely supervised, not only by McDonald's managers, but also by customers, whose constant presence exerted pressure to be diligent and speedy" (Leidner 1992, 160). In both of these studies, the workers were not only being held accountable by the organizational context, but also by their customers.

While doing gender is an important concept, in that it frames gender as socially constructed, it has limited ability to incorporate and critique power dynamics that are present in gender relations. Kimmel (2004) states: "Our social world is built on systemic structural inequality based on gender; social life reproduces both gender difference and gender inequality." (p. 113). In theorizing gender inequality as structural as well as interactional, it is possible to see the way in which doing gender, or specific performances, could possibly reproduce ideas and feelings about gender inequality. In the book Gender and Power, Connell (1987) outlines the power present in the process of doing gender by looking at hierarchical and socially privileged gender forms. In her analysis, she sees two socially idealized gender forms: hegemonic masculinity and emphasized femininity. Hegemonic masculinity is the dominant form of masculinity in a given society and "is always constructed in relation to various subordinated masculinities as well as in relation to women" (Connell 1987, p. 183). This type of masculinity is characterized by power, independence, strength, and emotional detachment. On the other hand, emphasized femininity is "organized as an adaption to men's power, and [emphasizes] compliance, nurturance and empathy as womanly virtues" (Connell 1987, p. 188). In her analysis, the power dynamic is present in the hierarchical arrangement of gender as well as the social privilege that accompanies certain gender performances.

\section{METHODS}

Data for this paper came from ethnographic research conducted for twenty-two hours over the course of eight weeks in a coffee shop located in an urban city in the Northwestern United States. The name of the coffee shop has been changed for purposes of confidentiality and will be referred to as The Coffee House. This coffee shop is frequented by students, as well as individuals that work on campus and at surrounding businesses, as it is located on the periphery of an urban University. The cafe is very large with ample amount of seating including couches, a large common table, bar-style seating, and two-seater tables. Most of the peripheral walls are composed of floor-to-ceiling length windows providing ample day time light. Where there are not windows, the walls are painted dark grey and are contrasted by the light, oak wood fixtures that line the area along the counters and bar. Music plays throughout the cafe just loud enough to cancel out the noise produced by the employees and machinery. Initially upon entering the store, customers are greeted by wall bays and shelving that are stocked with merchandise. As you continue walking there is a two-tiered pastry case that connects to the counter where two registers sit side-by-side. Orders are placed at the register and can be retrieved at the end of the bar area called the hand-off plane. People crowd around the handoff plane waiting for their name or order to be called for pick up. The lobby is always crowded either with new customers waiting in line or at the hand-off plane, or people occupying tables throughout the cafe.

At the time of this study, I had been employed at this coffee shop for a year and had been working in customer service for five years. As a barista, my job duties included ringing up purchases on the cash register, making drinks, cleaning, and supporting other coworkers. During my observation times, I was either ringing or making drinks in order to maximize interaction time with customers. My time at this site was concentrated mostly in the evening between the hours of 3 p.m. and 8 p.m. This period of time is quite a bit slower than the morning which allowed me to have longer interactions with customers as well as make jottings on receipt paper. After each shift, I would immediately type up the notes that I had made for the day in order to have fresh memories and detailed field notes. This customer-toworker interaction is an intimate one that gives insight into the way that customers do gender in such an organized public space.

My role as a participant observer in this site was known by my manager and coworkers, but was not known to customers. I felt that this was necessary in order to mediate routine work tasks while maximizing interaction time with customers. Due to my experience in customer service, I feel that I have a nuanced insight and developed understanding which allowed me to navigate the customer service environment and data collection process seamlessly. While conducting my research, I acted in accordance with all of The Coffee House's standards and 
policies and did not manipulate my interactions with customers as part of the research. However, due to my experience in the customer service industry and my familiarity with the customers it may have been possible that I was unable to be sensitive to the more mundane interactions with my customers which may have been counter to my findings. My past experiences may also have led to a predisposition to certain themes. While not all the themes that were present in the site our discussed at length in this paper it is important to recognize that my past experiences as a barista may have influenced the themes that I did end up choosing. The same interactions may have been interpreted differently or held more weight to someone that was not familiar with the environment.

\section{RESULTS}

Overall, individual's gender performances were quite normative, meaning men's adhered to hegemonic masculinity while women performed emphasized femininity (Connell 1987). The groups that most noticeably participated in normative gender performances were single men, single women, and heterosexual couples. First, I look at the way in which men and women perform gender when patronizing the Coffee House alone and how their gender performances embodied normative ideas of gender. And secondly, I look at the gender performances of heterosexual couples.

\section{HEGEMONIC MASCULINITY}

The majority of men's gender performances fell narrowly into the category of hegemonic masculinity. This particular gender performance was accomplished through assertions of normative forms of masculinity. Part of this gender performance of masculinity involved distancing from femininity. Connell (2005) states that hegemonic masculinity "essentializes male-female difference and ignores difference and exclusion within the gender categories" (p. 836). Therefore, men are able to effectively do hegemonic masculinity when they distance themselves from femininity and assert normalized and idealized forms of masculinity. What West and Zimmerman (1987) call "efficaciousness" sums up the gender performances among male customers at The Coffee House as individuals "were able to affect the physical and social environment through the exercise of physical strength or appropriate skills" (p. 141).

Men portrayed subtle forms of dominance through a multitude of means. The individuals in this site showed and exercised dominance most commonly through direct eye contact and assertiveness. In comparison with female customers, males had a tendency to make direct eye contact when ordering. In one particular instance, while ordering a drink, a male customer made very direct and intense eye contact with 
me which was uncomfortable to break. I had to break the eye contact in order to walk his drink to the bar. When I returned to the counter to complete his transaction he continued to stare intensely, not breaking eye contact. This counters the observation of female customers who did not engage in intense or prolonged eye contact. This is a gender performance that is rooted in dominance and played out by individuals that perform hegemonic masculinity.

This performance of hegemonic masculinity was also observable through the lack of emotion and empathy. In a customer service setting that is comprised of extensive emotional labor (Wharton 2009), men were at times apathetic to the overall customer service interaction and created physical and emotional distance from service workers. A middle-aged male customer came in and ordered a large Americano. He did not engage in dialogue with the two baristas at the bar and instead lingered awkwardly at the end of the hand-off plane, pacing from one position to another repeatedly while staring incessantly without engaging in small talk. He did not make eye contact or thank the baristas when they called out his drink. This man's interaction was detached, aloof, and further intensifies the overall understanding of doing gender at The Coffee House. Doing gender in a manner that aligns with hegemonic masculinity gives way to not only a personification of dominance, but also a lack of engagement. It is very common for customers to chat idly with baristas on bar as they make drinks. This ranges from very simple small talk to more personalized engagements depending on the relationship to the customer. However, this disregard for the emotional labor and customer service interaction serves as an emotional disconnect which is essential to the performance of hegemonic masculinity.

Men often performed hegemonic masculinity by distancing themselves from females and femininity. The dichotomous nature of masculinity and femininity permits masculinity to be justified through the rejection of all things that have been socially constructed as feminine. During one observation, a middle-aged male, dressed in a suit and tie, had been waiting for the men's restroom to become available for quite some time. There are two single-stall unisex bathrooms in the cafe that are assigned, unnecessarily, to a respective gender. I informed the man that the bathrooms were exactly the same and that he was more than welcome to use the women's restroom. He smirked and said that he was fine waiting. This type of interaction was not uncommon and works to fortify the idea of hegemonic masculinity and the distancing from what is identified as feminine. The business attired coupled with the sarcastic apprehension to step out of a male defined space and engage with what has been socially constructed as feminine extenuates the gender disparity that is reinforced by hegemonic gender performances.

Males that performed hegemonic masculinity were not only unwilling to engage with feminine space, but also created vocal rationalizations when they would engage with what is seen as the feminine. In many instances there were verbal accounts given by customers in reference to physical objects such as merchandise, food items, or drinks. A male approached the register and put both palms face down on the counter while he supported his upper body with his arms. He gazed up at the menus, scanning quickly and repeatedly without taking breaks or asking questions. After thinking for a while he stated that he didn't want to get a "foo foo" drink, but couldn't resist. While this individual did eventually choose a drink that he categorized as "foo foo," the dichotomized nature of gender remains. The vocalization that a particular drink is "foo foo" personifies a particular object as having feminine qualities. By explicitly stating that he did not want a "foo foo" drink it is clear that this individual was attempting to distance himself from appropriating culturally feminine objects. The vocal rationalization to me, the customer service worker, helped to mediate the negative associations that he had with femininity. In this way, it is possible to realize that this individual was very aware of the accountability that comes with doing gender and therefore felt that it was necessary to vocally rationalize his choice as he attempted to put one foot outside the box of traditional masculinity. In essence, he felt that his masculine performance was not compatible with a drink order he identified as feminine. By asserting traditional masculinity as separate from traditional femininity, males are able to secure their dominant gender position.

While hegemonic masculinity seemed to prevail in most of the interactions that I had with male customers over the course of my observations, this was not the sole form of doing gender for men. For example, the performance of alternative masculinities came into play when interacting with a collegeaged, Asian, male customer. He approached the register and immediately complemented my lipstick color. Meticulously 
dressed with a messenger bag draped over his shoulder, this individual was moderately effeminate. He paid in cash and when I gave him his change, he tossed it into the tip jar. This individual performed an alternative masculinity that was not constructed around dominance, but rather embraced feminine performance in dress and stature. He not only engaged in the customer service interaction, but chose to participate in the emotional labor that constitutes customer service work which can be seen through the extra dialogue that accompanied the normal small talk that is ubiquitous in almost all interactions. This is one example of the many alternative masculinities that were present in customer service interactions with men over the course of my observations. However, in general, hegemonic masculinity was the most prevalent form of gender presentation.

\section{EMPHASIZED FEMININITY}

In general, females patronizing the coffee shop alone performed emphasized femininity. West and Zimmerman (1987) state that this gender performance accentuates the portrayal of women as "ornamental objects" (p. 141). Here, the individual that is engaging with emphasized femininity becomes an ornamental object through the emphasis on appearance and material artifacts as well as the compliance exhibited during social interaction. More specifically, in this setting, emphasized femininity is characterized by timidity, lack of eye contact, indecisiveness, and need for apology. These characteristics perpetuate the idea of women as "ornamental objects" in that they are decorative and complicit. Connell (1987) elaborates on this by stating that emphasized femininity is "oriented to [accommodate] the interests and desires of men" (p. 183). Therefore, the compliance present in emphasized femininity works to enhance the dominance played out by hegemonic masculinity.

Many of the interactions that I had with females were comprised of timidity and apprehension. This contrasts greatly with the dominance that was portrayed by men. A young female came into the store and was very timid, not approaching the register or initiating conversation. When I approached the counter to ring her up I asked her how her day was going. She did not respond to the question and instead quietly said: "Small caramel latte. Extra hot, please." I quickly rang her up and said, "Thank you." She nodded her head, smiled, and turned to walk away. While this interaction at first glance may be deemed as a decisive and efficient, the real underpinnings reside in the body language and hesitation that was present prior to the interaction. Similar scenarios occurred during other observations. In another instance, an short woman with stark gray hair came into the store and ordered an eggnog latte. When I called the drink at the hand-off plane she walked up quickly grabbed the drink and nodded her head at me as she mumbled "thank you" under her breath. While these interactions parallel the emotional distance performed by male customers, they are not synonymous. For men, emotional distance was used as a way to disengage from the emotional labor present in customer service work which could be viewed as domineering from a customer service stand point due to the lack of emotional involvement. For women, the distance may be categorized by apprehension rather than disengagement. In this sense, females gender portrayal was less rooted in dominance and seemed to be more compliant and complimentary.

This emphasized femininity continues throughout the observations not only in the physical portrayal, but also the vocal indicators, or lack-there-of. During observations there was a college-aged, short female with long dark brown hair who came into the store. As I was ringing her up she changed her mind on what she wanted to order mid-transaction. She apologized profusely for her indecisiveness. I told her it was not a problem and proceeded to re-write her drink and re-ring her order. She paid, apologized again, and walked to the hand-off plane. The excessive apologizing following her discrepancy in ordering could be seen as sincerity, but can more closely be linked to passivity. This passivity was common in interactions with female customers, but was not present in interactions with male customers. Men rarely apologized for any discrepancy in an interaction which could be an extension of dominance and entitlement. Therefore, the passivity exhibited was inconsistent with the assertion displayed by males in the customer service realm further creating difference.

While women were physically timid and vocally passive, women also had a tendency to be limited in their decision making and were more inclined to comply with employee suggestions. This was of particular significance when listening to the conversations that one of my coworkers was having with a customer. As the business was slower at night and less steady, 
it was possible for employees to engage more extensively with customers. In one instance, a young, white female came into the store and was very indecisive about what she wanted to order. She asked one of my coworkers multiple questions about drink recipes. After my coworker offered five drink descriptions, the customer asked them for a personal suggestion. Following the suggestion, she agreed immediately without further questions. This type of compliance was a large component of performing emphasized femininity at The Coffee House. This type of interaction was exclusive to individuals that were not performing hegemonic masculinity. It was prevalent among individuals that participated in emphasized femininity and some alternative masculinities.

Not all women engaged in emphasized femininity. There were quite a few women I observed who performed alternative femininities. Of particular interest was an older female who had come into the store to purchase whole bean coffee. Upon entering the store, she walked to the coffee wall bay and without hesitation grabbed a pound of dark roast coffee. She approached the counter and pushed her coffee towards me and while digging through her wallet she said: "I need this ground on 7." I handed the coffee off to my bar help who worked on grinding the coffee for her. I returned to the register and inquired if she would like a drink today. She said that she would like an iced triple espresso in a medium cup with the shots on the bottom and the ice on top, not stirred or shaken. She insisted that the ice melts too fast. It was uncommon for females to be so detailed about their drink orders without prompts. However, this customer was scripted in her engagement and was decisive and assertive in regards to her needs. This deviation from the general trend is important in understanding that emphasized femininity is not the only way in which women performed gender at The Coffee House. However, the larger trend of emphasized femininity insinuates that it is important due to the prevalence across an array of customers and interactions. The gender performances exhibited by both males and females were even more extreme in the context of heterosexual couples.

\section{HETEROSEXUAL COUPLES}

Traditional gender performances were the most dominate and salient when interacting with individuals. This notion became even starker within the couple context. The relationship between individuals leads to a deeper understanding of the way in which gender is enacted in a customer service setting. In this instance, couples become an important sight of gender performances in that individuals are not only doing gender, but doing gender in relation to an oppositely gendered partner.

When engaging in small talk with couples, it was common that males dominated the conversation. For example, a young male and female came into the store and ordered beverages. I did not interact with them at the register, but made their drinks and interacted with them at the hand-off plane. I asked them what they were up to that evening. The male made eye contact and responded by saying: "I think we're just going to hang out and enjoy our evening." He then glanced at the female who smiled and looked at the floor while he proceeded to reciprocate the conversation by asking what I was doing with my evening. The female did not make eye contact or engage in dialogue and let her male partner guide the conversation. Here, the emphasized femininity that was observed becomes more prominent as the woman takes a submissive and compliant role in the interaction allowing the male to dominate and speak for the both of them. There were multiple instances in which this female submission, in the context of a heterosexual relationship, was prominent. During another observation a couple came into the store and approached the counter simultaneously, hand in hand. I asked them how their day was going, to which the male replied: "Very well, thank you." The female did not respond. I asked them what I could get them. The male looked at his female counterpart who shook her head, insinuating that he order first. He ordered a grande eggnog latte. The female abruptly ordered a tall of the same thing. The female then proceeded to pay without further discussion or eye contact. Regardless of her position as a provider, the female insisted that the male go first even though she had clearly known what she wanted. Even in the dominate role of paying the female took a submissive stance to ordering allowing her male counterpart to not only order first, but also carry the customer service interaction.

This female compliance and lack of interaction in the context of a customer service setting highlights the saliency of emphasized femininity in couple interactions. The ornamental nature of the female performing emphasized femininity was also present within couple interactions. In one instance, an young, Asian couple that were similar in height came in to the store. 
The male had his hair meticulously styled with a charcoal blazer and glasses. The female was wearing a navy blue Burberry coat and had her hair pilled effortlessly on top of her head in a bun. The male ordered a mocha and I inquired if he wanted whipped cream. The male cocked his head to his right to the look at his female counterpart who glanced up at him and shook her head. He turned back towards me and affirmed that the drink that he was ordering for the female did not have whipped cream. He then proceeded to order his own drink. In this instance, the male ordered for the female and the female did not engage in the customer service interaction at all. In this interaction the female acted in an ornamental fashion not only in appearance, but also in the act of compliance in reference to her male partner.

Not all heterosexual couples performed traditional gender roles, however. In one particular instance a college-aged couple came into the store. They approached the register in unison. The female stepped forward and ordered for both of them and continued to pay while the male stood behind and to the left of the female. When waiting for their drinks the male sat at the bar seating across from the hand-off plane while the female waited for their drinks. When the barista finished preparing the drinks, the female thanked him and carried her drink as well as her partner's to the bar seating. In this particular instance, the female took on a dominant role as provider while the male takes on a complicit role not only in regards to providing, but also in body language and lack of engagement. This role reversal was a notable exception to the general pattern.

In these gendered performances, males perform an active role while women seem to play a support role. Within couples, it is not that the submission or dominance is caused by the individuals, but rather that the structure of accountability inherent in doing gender could encourage the performance of emphasized femininity in relation to hegemonic masculinity. While not all individuals participated in normative gender performances, the prevalence of these performances creates a framework in which to analyze the larger structure under which doing gender is understood.

\section{DISCUSSION}

Overall, this research indicates that males and females performed traditional gender roles at The Coffee House. The dominant and active male role coupled with the complicit and passive female role dichotomizes performances of gender. Gender performances are context specific and therefore the particular performances exhibited by customers may not hold in all of their other social interactions. Therefore, these findings are not generalizable to all coffee shops or customer service jobs. However, gender performances change across settings and by studying people at this coffee shop it is possible to capture a snapshot of every day life and every day interaction. While it is important to not only understand the specific ways in which individuals do gender, it is also important to understand the larger implications of such gender performances.

When looking at heterosexual couples it was interesting to see the way in which normative gender performances were carried into the context of a relationship. The accountability in this type of a relationship could work to uphold social expectations of normative gender performances. The pressure of accountability in the public sphere seems to encourage traditional gender performance. Therefore, individuals are not only held accountable to social constructions of gender, but also to the individuals in which they are forming relationships with. While it was not possible to conclude that the gender performances of couples were the product of West and Zimmerman's (1987) notion of accountability, it is important to recognize the pressures that are placed on individuals in the public sphere by the organization, the customer service setting, and the other individuals in the setting. These coupled gender performances, however beneficial to social meaning and interaction, could potentially work to reinforce the idea of innate and biologically rooted gender. Creating and reinforcing the idea of essentialism perpetuates the inequalities that accompany the dichotomous notion of doing gender.

The performance of hegemonic masculinity and emphasized femininity in my site may reinforce or reproduce the idea of innate gender. Masculinity and femininity at large function in a fashion of mutual exclusivity. This is due, in part, to preconceived notions of gender performances as a result of inherent difference. The problem with essentializing the genders based solely on difference is that there is no room for overlap. This lack 
of overlap positions gender as a product of biology rather than society (Connell 1995). As long as such differences continue to be present between males and females in gender performance such actions will continue to uphold the inequalities that create discrepancies in the understanding and treatment of gendered bodies (Ridgeway 2011). This has powerful implications for individuals who are engaging in or participating in these traditional gender performances. The way in which customers interact with employees shapes and reinforces present notions of gender. Many of my coworkers are verbal about their understanding of male and female gender performances. At times, they were quick to assume passivity or compliance from female customers regardless of their engagement with emphasized femininity as well as assumed assertiveness and confidence in men regardless of the performances of hegemonic masculinity. In essence, they were quick to essentialize male and female behavior based on the traditional gender performances that took place at The Coffee House. Therefore, traditional gender performances were also upheld by my coworkers through their narratives of essentialist gender differences. This has serious implications in that such beliefs make it impossible for social actors to have agency or use resistance towards gender constructs leaving traditional performances as the only viable option. Therefore, the concept of doing gender and the prevalence of normative gender performances by patrons has serious implications for resistance and reinforcement.

\section{"Hegemonic masculinity establishes its hegemony partly by its claim to embody the power of reason, and thus represent the interests of the whole society." - Connell}

In my particular site it was obvious that hegemonic masculinity held privilege in respect to emphasized femininity it that it was preferred by my coworkers. These gender performances were preferred in that they more often resulted in fluidity, efficiency, and ease. These characteristics are highly valued in the world of corporate customer service and rationalization. The system of rationalization that has come to define the public and private spheres has become reliant on the values that are held within hegemonic masculinity. The ideas of being reliable, assertive, dominant, and independent are prevalent not only in the gender portrayals played out by males at The Coffee House, but are systemically bound to a larger system, in this case corporatism. Connell (1995) states that: "Hegemonic masculinity establishes its hegemony partly by its claim to embody the power of reason, and thus represent the interests of the whole society" (p. 164). Thus, this preference possibly comes from individual's larger desires for assertion and independence. In a world that is dominated by a global capitalist enterprise the dichotomized nature of masculinity seems to be the preferred gender display and therefore holds more access to privilege. In order to better understand gender it would be necessary to look into the deeper implications of how, or even if, these organizational settings and public spaces, like The Coffee House, not only result in, but also encourage traditional gender roles.

\section{LIMITATIONS}

Such considerations as my gender, time of day, and customer demographics are all variables that could not be controlled for and may have shaped the observations or interactions. Future research should look at the way in which customers' gender performances are affected by the gender of the worker. There were a couple instances in which male customers would engage with me in reference to an alternative masculinities, but engage with my male coworkers in reference to hegemonic masculinity. This obvious change in gender performance could have been attributed to the sex of the worker involved in the interaction. Also, due to my extended experience in customer service and my past familiarity with this particular coffee shop, it is possible to conclude that my observations may have missed some particular nuances in customer service interactions due to my familiarity with the routines, physical space, and customers. In order to make sure this was not a barrier it would have been necessary to 
carry out observations for a longer period of time in order to ensure that other gender performances were not being overlooked.

During my observations I was unable to collect substantial data on homosexual couples, therefore, I was only able to focus on heterosexual couples. However, Connell (1987) states that "the most important feature of contemporary hegemonic masculinity is that it is heterosexual" (p. 186). Since, hegemonic masculinity was so salient in this particular location it would have been interesting to have had data to compare and contrast to heterosexual couples. Therefore, future research should look at the ways in which homosexual couples do gender and the ways in which accountability is enacted in social interaction. Of particular interest would be whether doing gender for these couples is used a mechanism of resistance or compliance.

Due to the location of this particular coffee shop it is impossible to consider the results of this study to be generalizable to other coffee shops or other universities. This university in particular is nontraditional due to its urban location and student demographic (e.g. International students and high transfer rate). Such individual gender performances vary across time and place creating a complex system of understanding that is rooted in social and cultural meaning. Therefore, intersectional approaches should be incorporated into future research on doing gender. While gender is an important and salient social identity, it is not a singular identity, and instead is informed by many other coexisting identities. Even though these findings are not generalizable they do give insight into the way in which gender is not an individual identity, but rather a social accomplishment. 
This work is licensed under a Creative Commons Attribution-

NonCommercial-

NoDerivs 3.0

Unported License.

\section{BIBLIOGRAPHY}

Connell, R.W. 1987. Gender and Power. Stanford, CA: Stanford University Press.

Connell, R.W. 2005. "Hegemonic Masculinity: Rethinking the Concept." Gender and Society 19(6): 829-859.

Connell, R.W. 1995. Masculinities. Los Angeles: University of California Press.

Davies, Karen. 2003. "The Body and Doing Gender: The Relationship Between Doctors and Nurses in Hospital Work." Sociology of Health and Illness 25(7): 720-742.

Forseth, Ula. 2005. "Gender Matters? Exploring How Gender is Negotiated in Service Encounters." Gender Work and Organization 12(5): 440-459.

Hall, Elaine.1993. "Smiling, Deferring, and Flirting: Doing Gender by Giving 'Good Service."' Work and Occupations 20(4): 452-471.

Hall, Elaine. 1993. “Waitering/Waitressing: Engendering the Work of Table Servers." Gender and Society 7(3): 329-346.

Kimmel, Michael. 2004. The Gendered Society. New York: Oxford University Press.

LaPointe, Eleanor. 1992."Relationships with Waitresses: Gendered Social Distance in Restaurant Hierarchy." Qualitative Sociology 15(4): 337-393.

Leidner, Robin. 1991. "Serving Hamburgers and Selling Insurance: Gender, Work, and Identity in Interactive Service Jobs." Gender and Society 5(2): 154-177.

Rabe-Hemp, Cara. 2009. "POLICEwomen or PoliceWOMEN? Doing Gender and Police Work." Feminist Criminology 4(2): 114-129.

Ridgeway, Cecilia. 2011. Framed By Gender. New York, New York: Oxford University Press.

Trautner, Mary Nell. 2005. “Doing Gender, Doing Class: The performance of sexuality in Exotic Dance Clubs." Gender and Society 19(6): 771-788.

West, Candance and Don Zimmerman. 1987. "Doing Gender." Gender and Society 1(2): 125-151.

Wharton, Amy. 2009. "The Sociology of Emotional Labor." Annual Review of Sociology 35: 147-165. 